\title{
Numerical Simulation of Fire Growth, Transition to Flashover, and Post-Flashover Dynamics in the Dalmarnock Fire Test
}

\author{
MARIANO LAZARO ${ }^{1}$, HAVARD BOEHMER ${ }^{2}$, DANIEL ALVEAR ${ }^{1}$, JORGE A. CAPOTE $^{1}$ and \\ ARNAUD TROUVE ${ }^{2}$ \\ ${ }^{1}$ Group GIDAI \\ University of Cantabria \\ Santander 39005, Spain \\ ${ }^{2}$ Department of Fire Protection Engineering \\ University of Maryland \\ College Park, Maryland 20742, USA
}

\begin{abstract}
The objective of the present study is to evaluate the ability of current Computational Fluid Dynamics (CFD) tools to simulate compartment fires with flashover followed by under-ventilated and/or quasistoichiometric, partially-under-ventilated conditions. Current CFD capabilities are illustrated using the Fire Dynamics Simulator (FDS, Version 5), developed by the National Institute of Standards and Technology, USA. The FDS modeling capability is evaluated by detailed comparisons with an experimental database previously developed by the University of Edinburgh, UK. The test configuration corresponds to a fullscale fire test known as the Dalmarnock fire test (test 1). The description of the flammable content in the fire room is based on a standard modeling approach in which the ignition time of flammable objects and materials is calculated using a local heat transfer solver, while the fuel mass loss rate after ignition is prescribed using experimental data from cone/furniture calorimeter tests. The simulated Dalmarnock fire scenario includes flashover, a first post-flashover stage that is under-ventilated and characterized by burning outside the fire room, and a second post-flashover stage that is partially-under-ventilated and characterized by distributed burning inside the fire room. Transition to this second stage is triggered by window breakage in the fire room. The different stages of the fire scenario are analyzed in terms of the fire room global equivalence ratio (GER), which is considered as the main controlling parameter of the fire behavior. Comparisons between numerical results and experimental data are relatively good when considering the global features of the fire dynamics, e.g., the time history of the spatially-averaged heat release rate. Comparisons are not as good when considering local features, e.g., the time history of gas or wall temperatures, or that of wall heat fluxes.
\end{abstract}

KEYWORDS: fire modeling, CFD, fire growth, compartment fires, flashover, post-flashover, global equivalence ratio, Dalmarnock.

\section{INTRODUCTION}

Compartment fires exhibit unique features associated with the presence of multiple/complex fuel sources, smoke accumulation, restricted air ventilation, and interactions between flames and solid walls [1-3]. A typical compartment fire scenario evolves through a succession of stages, for instance: an ignition stage corresponding to the thermal degradation of an initial fuel source, followed by the start of flaming combustion and the early fire growth; a pre-flashover stage featuring a well-ventilated (i.e., fuel-limited) fire and a growing hot smoke layer near the compartment ceiling (this layer contributes in turn to the intensification of heat exchanges - in particular thermal radiation exchanges - and promotes faster fire growth); a flashover stage that corresponds to a series of spontaneous ignition events driven by high irradiation levels from super-hot ceiling layer gases (i.e., gases with temperatures in excess of 800-900 K) and results in a full involvement of all flammable contents in the fire room; a post-flashover, fullydeveloped stage featuring a ventilation-controlled (i.e., oxygen-limited) fire and often resulting in external burning and fire spread from the room of fire origin to adjacent compartments.

An important parameter that characterizes the compartment fire behaviour is the global equivalence ratio (GER). GER is defined as the averaged fuel-to-oxygen mass ratio in the fire room divided by its stoichiometic value. Note that the stoichiometric value of the fuel-to-oxygen mass ratio may not be known or even well defined in a real-world compartment fire scenario (because of both the heterogeneity of the fuel sources and the unknown chemical composition of the fuel vapors); in that case GER cannot be 
evaluated. When this ratio can be evaluated, however, GER becomes a convenient marker to monitor the fire room conditions. For instance, at low values of GER, GER $\leq 0.3-0.5$, the fire is well-ventilated; under these conditions, the flames are located in the immediate proximity of the fuel sources and are characterized by high values of the combustion efficiency and low values of the carbon monoxide and soot yields. In contrast, at high values of GER, GER $\geq 1$, the fire is under-ventilated; under those conditions, the fire evolves to one of the following two regimes: a complete extinction regime in which the combustion is dominated by the adverse effects of air vitiation and oxygen starvation; or an external-burning regime in which the flames successfully migrate from the fuel sources to the compartment vents and continue to burn outside. Intermediate values of GER, $0.3-0.5 \leq$ GER $\leq 1$, correspond to a transitional regime; as GER $\rightarrow 1$, this regime is characterized by decreasing values of the combustion efficiency (i.e., higher probabilities of local flame extinction events) and increasing values of the carbon monoxide and soot yields.

Computational Fluid Dynamics (CFD) has emerged in recent years as a powerful approach to bring unique scientific and/or engineering information on the dynamics of compartment fires. CFD-based fire modeling is now a well-established approach, and is routinely used for design and analysis tasks in a number of application areas, including performance-based design, forensic investigations, fire-fighter training, emergency management applications, and risk analysis. While the state-of-the-art continues to change rapidly, the domain of application of current CFD-based fire models remains largely limited to a simplified strategy in which the fuel mass loss rate is prescribed (i.e., treated as an input quantity - for instance, using experimental measurements - as opposed to being calculated as a function of the fire thermal feedback). In the context of this simplified strategy, many studies have shown that CFD-based fire models perform well when applied to scenarios that correspond to well-ventilated conditions [4]. Some recent studies, however, also suggest that while fire models perform surprisingly well when applied to under-ventilated fires, they perform poorly in the transitional regime, i.e., for $0.3-0.5 \leq \mathrm{GER} \leq 1$ [5]. Thus, it may be concluded that the greatest challenge in compartment fire modeling is found in the simulation of quasi-stoichiometric compartment fires. And this challenge becomes even more formidable when the fuel mass loss rate is treated as a solution variable instead of being prescribed.

The general objective of the present study is to evaluate the ability of current fire modeling tools to simulate compartment fires. We consider in the following a test configuration corresponding to a full-scale fire test known as the Dalmarnock fire test [6-9] (two tests were in fact conducted, but we limit here the scope of our discussion to test 1 , see Refs. [6-7,9] for details). The Dalmarnock test was performed in July 2006 by the fire research group at the University of Edinburgh in a high-rise building located in Glasgow, UK. The test was set in a two-bedroom flat located on the $4^{\text {th }}$ floor; the flat was empty except for the lounge that was furnished (using typical furniture items and a representative layout) and that was treated as the fire room. The fuel load density in the fire room was estimated to be $32 \mathrm{~kg} / \mathrm{m}^{2}$ of wood equivalent. The lounge was ventilated by open doorways to the kitchen (featuring a partially-open window) and to the entrance hallway (featuring an open front door). In addition, one lounge window was partially broken by external intervention at a given time ( $t=13$ min after ignition) while the other window broke spontaneously at a much later time $(t=19 \mathrm{~min}$ after ignition). The outdoor wind was weak during the test (with mean velocities between 1 and $2 \mathrm{~m} / \mathrm{s}$ and blowing into a direction parallel to the lounge windows [8]) and is not believed to have been an important factor in the overall fire dynamics. The fire room was heavily instrumented with video imaging cameras, thermocouple trees, heat flux gauges, bi-directional flow velocity probes, laser extinction meters, and smoke detectors. The fire was ignited using a plastic waste basket filled with newspaper previously soaked with heptane and located close to a two-seat sofa stuffed with polyurethane foam. Observations and measurements helped identify the following stages in the fire scenario: the fire first grew gradually, initially fueled by the burning of the waste basket and sofa; flashover was observed at approximately $t=5 \mathrm{~min}$, shortly after a bookcase ignited; the fire subsequently showed signs of poor ventilation; the fire intensity increased again when the fire room window was broken $(t=13$ min) thereby confirming under-ventilated fire conditions; the fire was extinguished by firefighter intervention at $t=20 \mathrm{~min}$.

The Dalmarnock fire test data have been used by the University of Edinburgh to organize a "round-robin” 


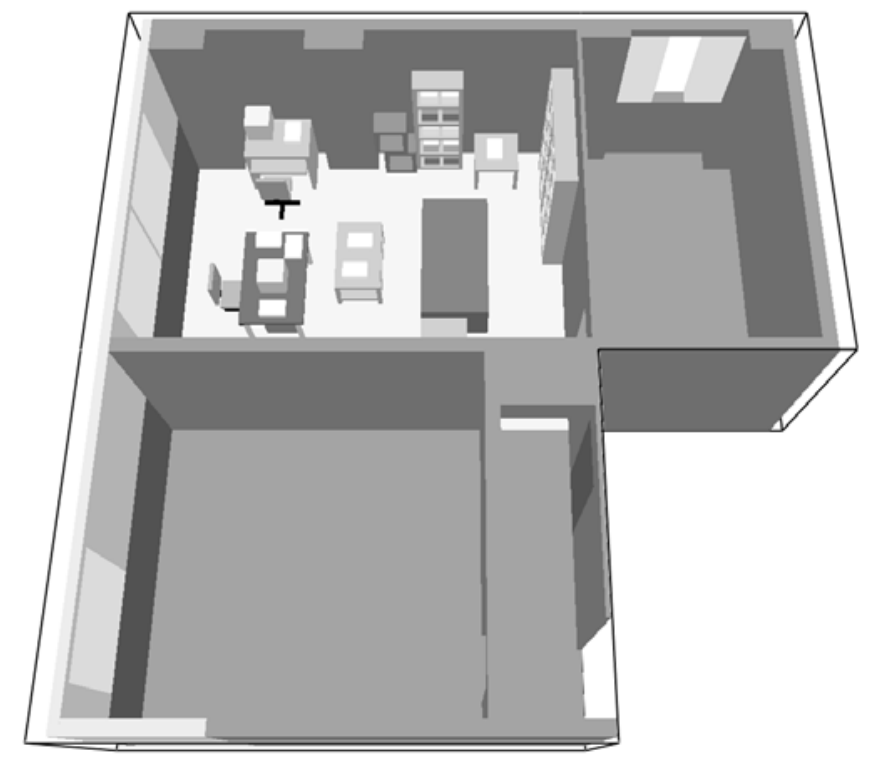

Fig. 1. Smokeview representation of the flat used in the Dalmarnock fire test. The FDS computational domain corresponds to the furnished lounge (upper left), the kitchen (upper right), a bedroom (lower left) and the entrance hallway (lower right).

study [6-7,9]. The "round-robin" study consisted in bringing together several independent teams of fire model practitioners and in asking each team to perform a priori simulations (i.e., blind simulations without access to experimental results) of the Dalmarnock test configuration. Input data were provided to all teams, including the flat geometry, a detailed description of the fuel load and ventilation conditions, and the time histories of the heat release rate of the first burning elements (i.e., the waste basket and the sofa - as obtained from a separate furniture calorimeter test). Interestingly, while most teams chose to use the same CFD fire model (the Fire Dynamics Simulator), the teams also produced widely different results, primarily due to different choices made in the characterization of the flammable objects and materials present in the fire room. The large scatter in the results collected by the University of Edinburgh is thought-provoking and suggests that consistent with our previous discussion on GER, the level of maturity of CFD-based fire models for realistic compartment fire scenarios with flashover and under-ventilation is still inadequate. Note that this comment refers not only to the CFD solver itself, but also to the availability and quality of input data (in particular with respect to the description of the flammable content) and to the knowledge base that may be used to assist practitioners.

The present study is a continuation of this previous work on the Dalmarnock fire test in Refs. [6-7,9] and an extension to a posteriori simulations (i.e., simulations conducted with full access to experimental results). This study is similar to the one recently presented in Ref. [8]. The numerical simulations are performed using the Fire Dynamics Simulator (FDS) Version 5. FDS is developed by the National Institute of Standards and Technology (NIST), USA, and is oriented towards fire applications; it uses a Large Eddy Simulation approach for turbulence (based on the classical Smagorinsky model), a conditional fast chemistry model for non-premixed combustion (based on the Eddy Dissipation Concept and an air-vitiation flame extinction model), a mixture-fraction-based model for soot formation (based on a soot yield), and a radiative-transfer-equation model for thermal radiation transport (based on a gray gas or a wide band treatment) [10-12]. The next Section presents the experimental and numerical configurations. The subsequent Section presents a detailed comparison between experimental data and numerical results.

\section{DALMARNOCK FIRE TEST CONFIGURATION}

A computer representation of the fire test geometry was produced based on the description, blueprints and photographs made available by the University of Edinburgh [6-9]. The numerical configuration is presented in Fig. 1 using the Smokeview graphics software [13]; it includes the fire room (the lounge), the kitchen, one of the two bedrooms and part of the entrance hallway. Windows are identified in Fig. 1 as light grey surfaces on the vertical walls. The bedroom has a closed window and is not considered as a critical 
component of the configuration. In contrast, the kitchen has a partially-open window and the entrance hallway has an open door; both openings play a critical role in determining the ventilation conditions in the lounge. Figure 1 also shows the two windows present in the lounge (one of which is broken at $t=13$ min after ignition). The furniture in the lounge includes: a sofa (the item where the fire starts; the sofa is visualized in Fig. 1 as a rectangular block colored in dark grey and is located slightly to the right of the center of the room); three wall-mounted bookcases filled with paper items; two computer desks, each with a computer and chair and located near the windows; one coffee table and two low tables with paper stacks.

The FDS simulation matrix corresponds to four cases including two grid resolution levels and two different combustion modeling choices. The computational grid is a rectangular mesh; the lounge is $4.75 \mathrm{~m}$ long, $3.50 \mathrm{~m}$ wide and $2.45 \mathrm{~m}$ high; the grid is a uniform cubic mesh in the lounge and the grid cell size is $\Delta=5$ or $10 \mathrm{~cm}$; the corresponding total mesh size is 967500 or 129600 cells. The FDS description of combustion uses a non-premixed combustion model known as the Eddy Dissipation Concept [11-12]; this model includes an air-vitiation flame extinction model that may or may not be activated; the simulations are run twice, with and without flame extinction.

We now turn to a discussion of the FDS descriptions of air ventilation and fuel supply during the development of the fire. One of the two (glass) windows in the lounge is open at a user-prescribed time, $t=$ $780 \mathrm{~s}$ (13 min); the opening of the second window is controlled by a window breakage algorithm using a FDS temperature sensor and a critical temperature of $100{ }^{\circ} \mathrm{C}$. This critical value of the temperature was previously determined using the BREAK1 model developed at the University of California at Berkeley and made available by NIST [14].

The fuel associated with burning elements is treated as $C_{6.3} H_{7.1} N_{2.1}$ (a composition that is often used to characterize fuel vapors from polyurethane foam undergoing pyrolysis); the corresponding heat of combustion (per unit mass of fuel) is $\Delta H_{\mathrm{F}}=19043 \mathrm{~kJ} / \mathrm{kg}$. The waste basket and sofa are lumped into a single element; the combustion of this first burning element is described using a prescribed time history of the fuel mass loss rate taken from Ref. [15] (Fig. 2). Note that the variations in Fig. 2 differ from those proposed in the "round-robin" study of Refs. [6-7,9]; a different sofa burning pattern was presented in Refs. [6-7,9] based on a separate furniture calorimeter test performed at the University of Edinburgh. The Edinburgh calorimeter data, however, were later found to be problematic (when used in simulations, these data lead to large underestimates of the growing fire size) and are probably incorrect [8].

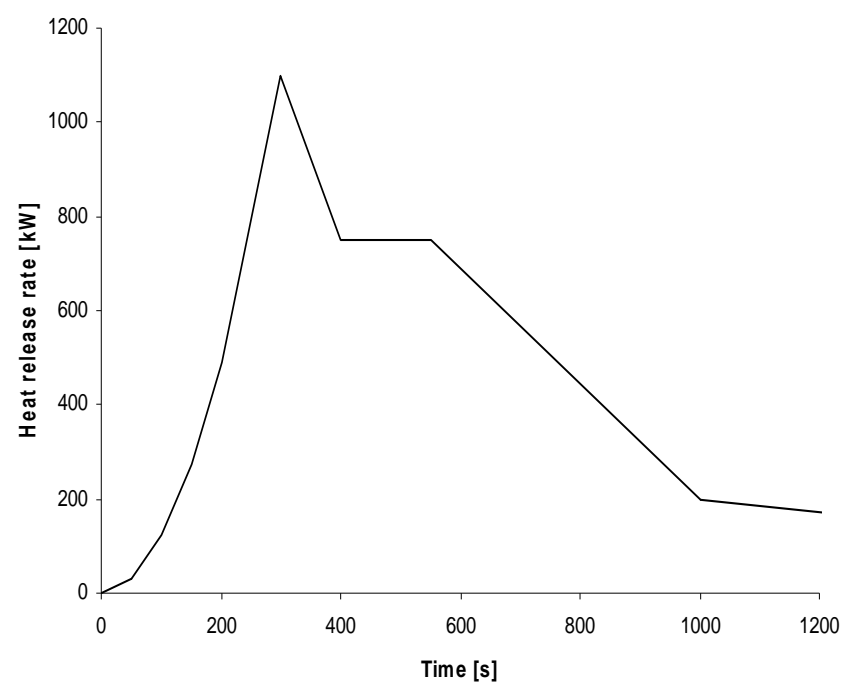

Fig. 2. Time history of the heat release rate of the sofa/waste-basket element, adapted from Ref. [15]. 

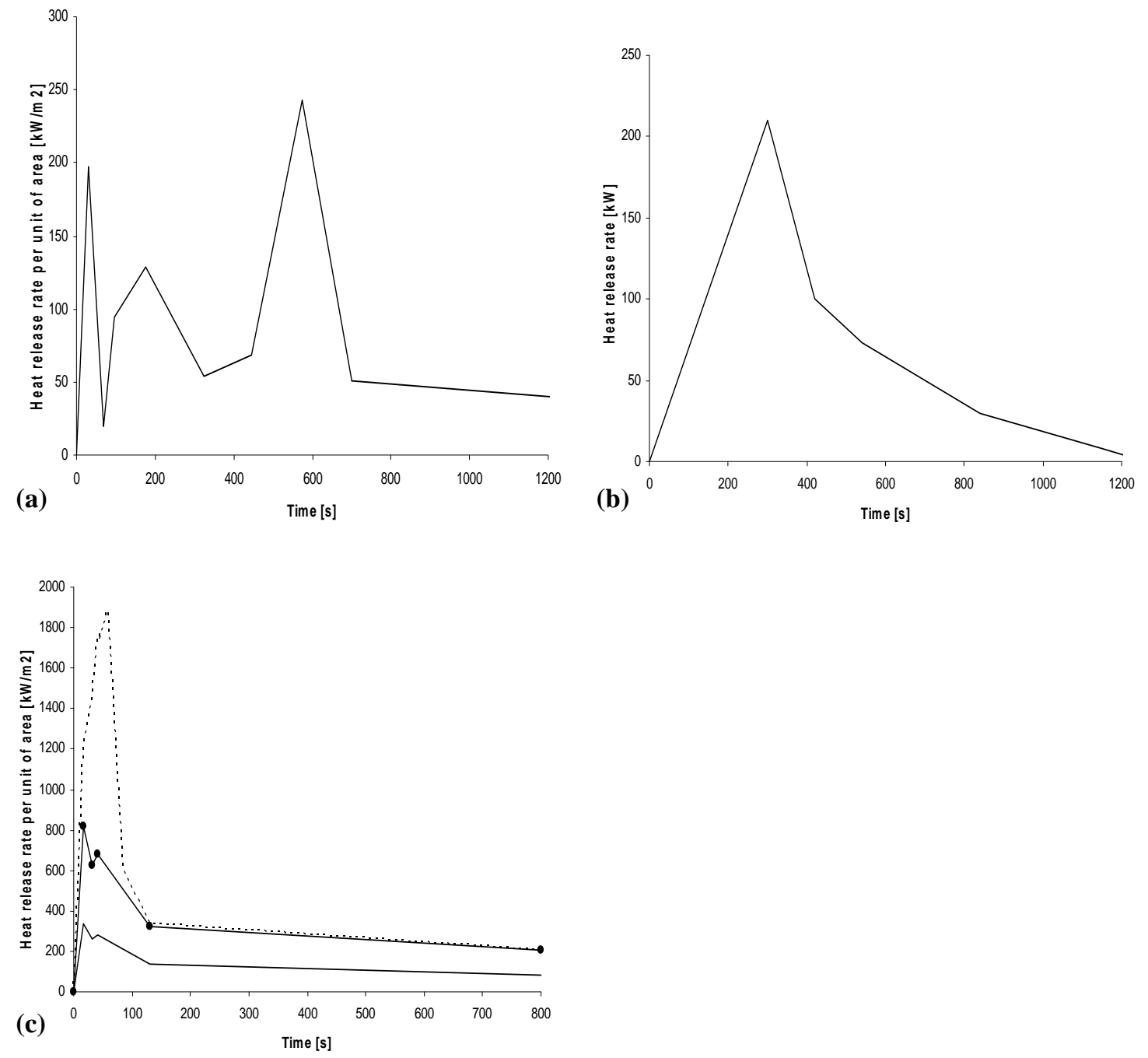

Fig. 3. Time history of the heat release rate of: (a) wood materials, adapted from Ref. [18]; (b) computer monitors, adapted from Ref. [20]; (c) horizontal paper stacks (solid line), vertical paper stacks (solid line with dot symbols), letter trays (dashed line), adapted from Ref. [21].

The pyrolysis of other flammable objects and materials in the fire room is described using a standard modeling approach in which time to ignition is calculated using the solid heat conduction solver available in FDS combined with (for each fuel source) material properties and an estimate of the ignition temperature, while the fuel mass loss rate after ignition is prescribed using experimental data from cone/furniture calorimeter tests. For instance, the ignition of wood objects (desks, bookcases, tables) is described using plywood material properties [16] and an estimate of the wood ignition temperature (we use $326{ }^{\circ} \mathrm{C}$ [17]), while the subsequent pyrolysis is described using data from Ref. [18] (Fig. 3(a)). Similarly, the ignition model for the two computer monitors uses material properties for plastics [19] and an estimate of the ignition temperature (we use $200{ }^{\circ} \mathrm{C}$ [19]), while the pyrolysis model uses data from Ref. [20] (Fig. $3(\mathrm{~b}))$.

Other important fuel sources in the lounge include paper stacks and plastic letter trays that are present on the desks, tables and bookshelves. The paper-stack/letter-tray ignition model uses material property data from Ref. [19] and an estimate of the ignition temperature (we use $369^{\circ} \mathrm{C}$ [19]). The pyrolysis model uses data from Ref. [21] (Fig. 3(c)). The paper stacks are divided into two groups: horizontal stacks located on the desks and tables; and vertical stacks located on the bookshelves. As shown in Fig. 3(c), the burning curve of the vertical stacks is corrected in order to account for the likely discrepancy between the number 
of fire-exposed surfaces in real and simulated stacks (FDS tests reveal that the simulated paper stacks inside the bookcases have only one or two fire-activated surfaces whereas real paper stacks might feature three or four. To account for this discrepancy, the fuel mass loss rate - per unit fuel source area - of vertical paper stacks is multiplied by a factor of 2.4).

The computer chairs are treated as made of upholstery (seat and back) and plastic (legs). The chair ignition model uses material property data obtained from both the database of FDS Version 4 and Refs. $[3,19]$. The pyrolysis model adopts a more elaborate modeling approach in which the fuel mass loss rate is calculated as a function of the fire thermal feedback. Similarly, the ignition model of the floor carpet uses material property data proposed in the database of FDS Version 4; and the carpet pyrolysis model uses a thermalfeedback-sensitive model. The impact of the chair and carpet burning models on the overall fire dynamics is believed to be small.

Simulations were performed on a multi-processor Windows cluster available at the University of Cantabria and on a Linux cluster available at the University of Maryland, using the parallel MPI-based version of FDS.

\section{RESULTS}

\section{Variations of the Heat Release Rate}

Figure 4 presents the time variations of the global (spatially-averaged) heat release rate, as obtained in the four different FDS simulations considered herein, with $\Delta=5$ or $10 \mathrm{~cm}$, and with or without flame extinction. Consistent with experimental observations (see the Introduction Section), the simulations suggest that the fire goes through a succession of stages: (1) a pre-flashover stage ( $0 \leq t \leq 300 \mathrm{~s}$ ) during which the fire size grows to approximately $1 \mathrm{MW}$; (2) flashover at time $t \approx 300 \mathrm{~s}$; (3) a first post-flashover stage (300 $\leq t \leq 780 \mathrm{~s}$ ) during which the fire size is approximately 3-4 MW; (4) a first (controlled) window breakage in the fire room at time $t=780 \mathrm{~s}$; (5) a second post-flashover stage (780 $\leq t \leq 1000 \mathrm{~s})$ during which the fire size reaches 5-6 MW (note that this value corresponds to the heat release rate inside the flat and does not account for the additional combustion power associated with external flames at the lounge windows); (6) a second (uncontrolled) window breakage in the fire room at time $t \approx 900 \mathrm{~s}$, which has no visible impact on the fire size (this second window breakage is observed in the $\Delta=5 \mathrm{~cm}$ solution but at an incorrect time $-t \approx 900 \mathrm{~s}$ compared to $t=19 \mathrm{~min} \approx 1100 \mathrm{~s}$ in the test - and is not observed in the $\Delta=10$ $\mathrm{cm}$ solution); (7) a decay stage ( $t \geq 1000 \mathrm{~s}$ ) during which the fire size is observed to decrease (further analysis suggests that this decrease is the consequence of fuel depletion). The simulations are terminated at time $t=1200 \mathrm{~s}$, which corresponds to the recorded time of intervention of the fire brigade.

Figure 4 shows that variations between the different FDS simulations are moderate. Simulations with flame extinction (Fig. 4(a)) predict a fire size that is approximately 15\% smaller than that obtained in simulations without extinction (Fig. 4(b)). The effect of changing the computational grid size is somewhat larger and corresponds to approximately 30\% variations in the predicted fire size; this sensitivity of the simulation results to grid resolution is a concern and indicates that the present results remain grid-dependent.

In Fig. 4, the FDS results are also compared to experimental estimates [6-9]. These estimates are based on measurements of the air inflow velocity in the kitchen, entrance hallway, and at the lounge windows; they assume that the fire is under-ventilated and that all the oxygen flowing into the lounge area is actually consumed by combustion; these estimates are therefore limited to the post-flashover stages $(t \geq 300 \mathrm{~s})$. The experimental data imply a fire size of $3 \mathrm{MW}$ during the first post-flashover stage and $5 \mathrm{MW}$ during the second stage. The comparison between experimental estimates and FDS results is encouraging, especially with regard to predictions of both the timing of flashover and the response of the fire to the first window breakage at $t=780 \mathrm{~s}$. 

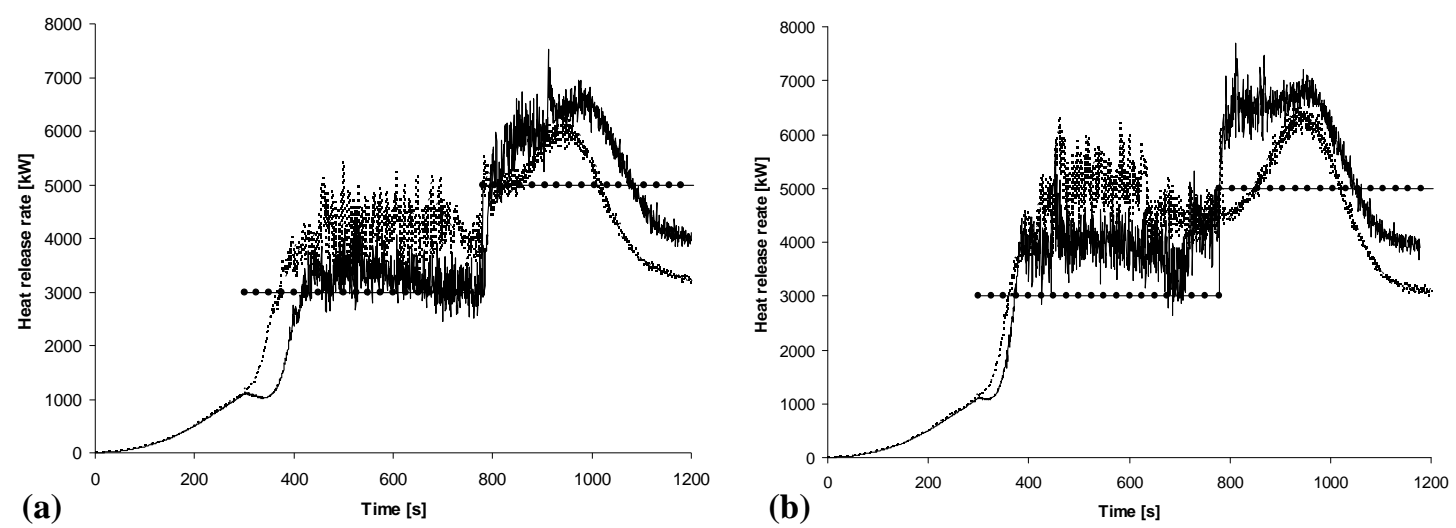

Fig. 4. Time variations of the global heat release rate. Comparison between fine-grid ( $\Delta=5 \mathrm{~cm}$, solid line) and coarse-grid ( $\Delta=10 \mathrm{~cm}$, dashed line) simulations; the solid line with dot symbols represents experimental estimates [6-9]. FDS results obtained: (a) with flame extinction, (b) without flame extinction.

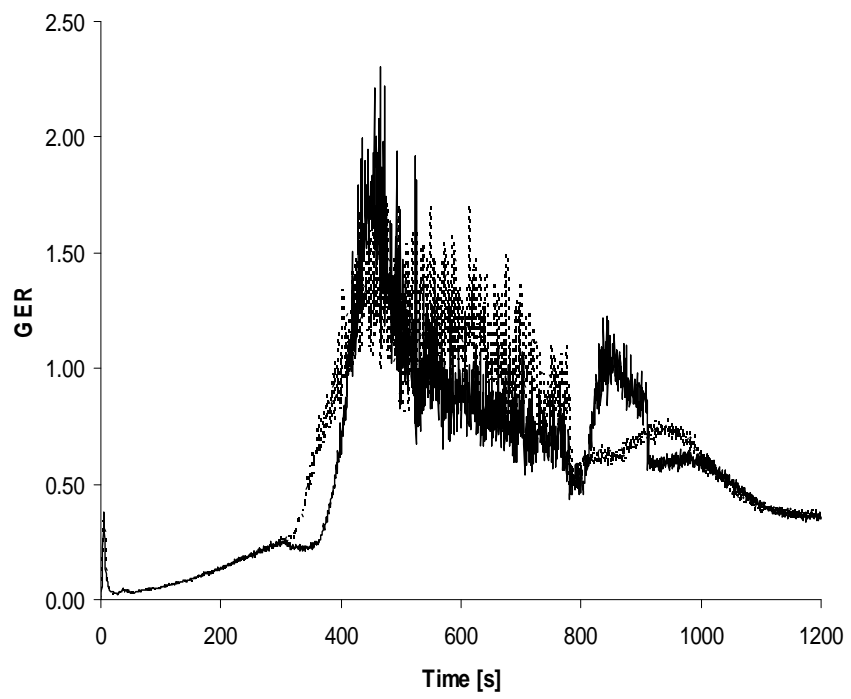

Fig. 5. Time variations of the fire room global equivalence ratio (GER). Comparison between fine-grid ( $\Delta=$ $5 \mathrm{~cm}$, solid line) and coarse-grid ( $\Delta=10 \mathrm{~cm}$, dashed line) simulations.

\section{Variations of the Global Equivalence Ratio}

We focus in the remainder of the paper on FDS results obtained with flame extinction (we believe that the flame extinction model adds to the realism of the simulations, at least in a qualitative sense) and turn in this Section to a discussion of the ventilation conditions inside the fire room. Figure 5 presents the time variations of the fire room global equivalence ratio, defined as:

$\mathrm{GER}=\left(\frac{r_{s}}{Y_{O 2, A i r}}\right) \times\left(\frac{\dot{m}_{F}}{\dot{m}_{\text {Air }}}\right)$

where $r_{\mathrm{s}}$ is the stoichiometric oxygen-to-fuel mass ratio, $r_{\mathrm{s}} \approx 1.45, Y_{O 2, \text { Air }}$ the oxygen mass fraction in 

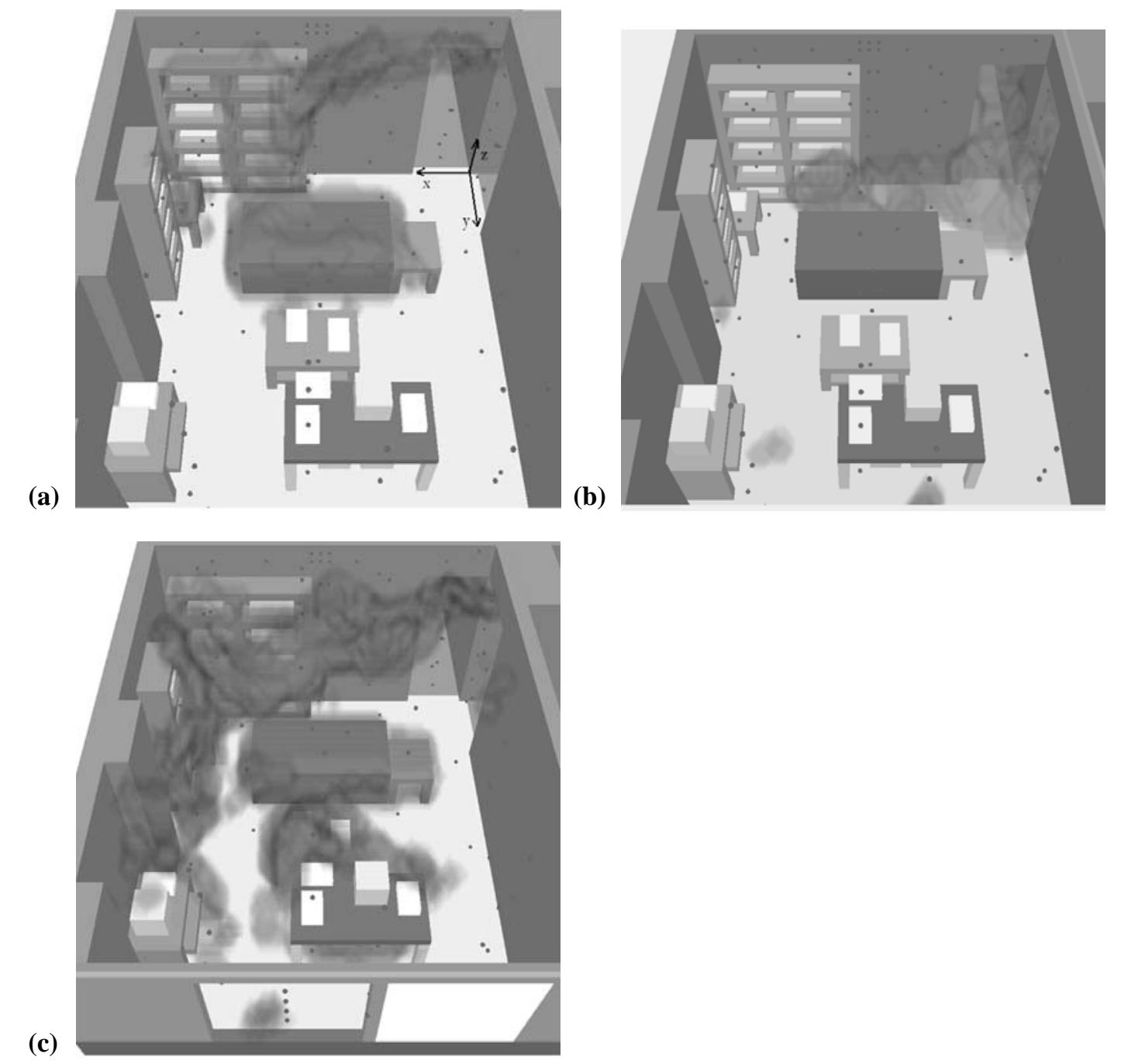

Fig. 6. Smokeview visualization of the instantaneous flame location (using an iso-contour of the heat release rate per unit volume). (a) $t=350 \mathrm{~s}$; (b) $t=480 \mathrm{~s}$; (c) $t=810 \mathrm{~s} \mathrm{(} \Delta=10 \mathrm{~cm}$ solution).

ambient air, $Y_{O 2, A i r} \approx 0.233, \dot{m}_{F}$ the total fuel mass loss rate (averaged over all fuel sources), and $\dot{m}_{A i r}$ the total air mass inflow rate though the lounge doorways and windows (when broken). Both $\dot{m}_{F}$ and $\dot{m}_{\text {Air }}$ can easily be extracted from the FDS solutions.

Figure 5 shows that the fire becomes under-ventilated (GER $\geq 1$ ) at flashover $(t \approx 300 \mathrm{~s}$ ) and then slowly evolves to a transitional regime $(0.3-0.5 \leq$ GER $\leq 1)$ during the first post-flashover stage (300 $\leq t \leq 780 \mathrm{~s})$. Further analysis indicates that this evolution to fuel-leaner conditions is driven by decreasing values of $\dot{m}_{F}$ (a consequence of fuel depletion and lower in-room burning intensities), while $\dot{m}_{\text {Air }}$ remains approximately constant. The first window breakage at time $t=780 \mathrm{~s}$ results in a slight drop in GER (due to increasing values of $\dot{m}_{\text {Air }}$ ) followed by a sharp rise (due to the subsequent intensification of the fire and associated increasing values of $\dot{m}_{F}$, see Fig. 4). The fire remains in a transitional regime during the second postflashover stage (780 $\leq t \leq 1000 \mathrm{~s})$ and the decay stage ( $t \geq 1000 \mathrm{~s}$ ). In the $\Delta=5 \mathrm{~cm}$ solution, the second window breakage ( $t \approx 900 \mathrm{~s}$ ) leads to a noticeable drop in GER; this drop is not observed in the $\Delta=10 \mathrm{~cm}$ solution. 


\section{Variations in the Flame Structure}

Flame visualization provides additional insight into the simulated fire dynamics (Fig. 6). For instance, at time $t \approx 160 \mathrm{~s}$, the fire is observed to spread from the sofa/waste-basket element to the small table next to it, and then, at time $t \approx 315 \mathrm{~s}$, to the nearest bookcase (Fig. 6(a)). Consistent with experimental observations [6-9], the ignition of a bookcase is the triggering event that explains transition to flashover. After flashover has occurred, the fire becomes under-ventilated (Fig. 5), oxygen is depleted from the fire room, and the flames migrate to the two room doorways (Fig. 6(b)). Following the first window breakage ( $t=780 \mathrm{~s}$ ), the inflow of new fresh air into the fire room leads to a dramatic change in the flame structure and the flames move back into the fire room (Fig. 6(c)). A comparison between Figs. 6(b) and 6(c) suggest that while the first post-flashover stage corresponds to an under-ventilated combustion regime, the second post-flashover stage may be better described as a partially-under-ventilated combustion regime, in which pockets of fuelrich and oxygen-rich gases interact, mix and burn in a distributed combustion zone. At the time of the second window breakage ( $t \approx 900 \mathrm{~s}$ ), the inflow of additional fresh air into the fire room does not provoke a radical change in the flame structure. Note that both the fine grid solution $(\Delta=5 \mathrm{~cm})$ and the coarse grid solution $(\Delta=10 \mathrm{~cm})$ reveal similar flame structures.

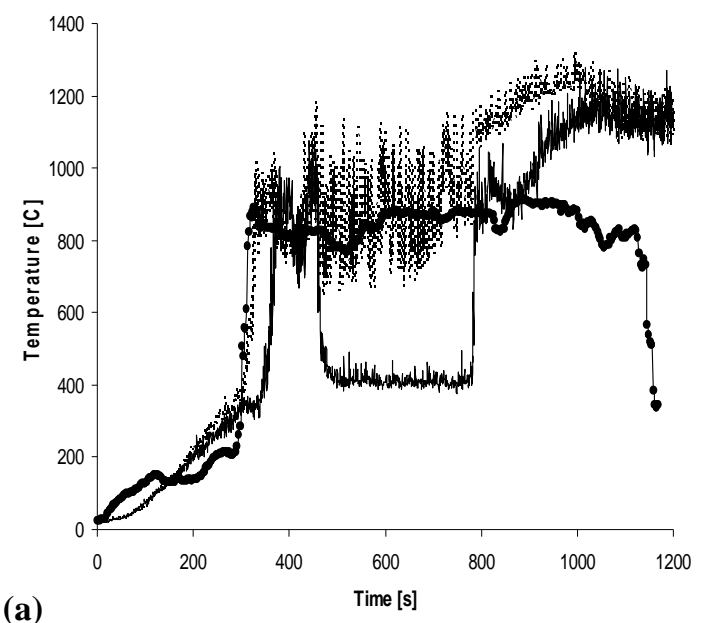

(a)
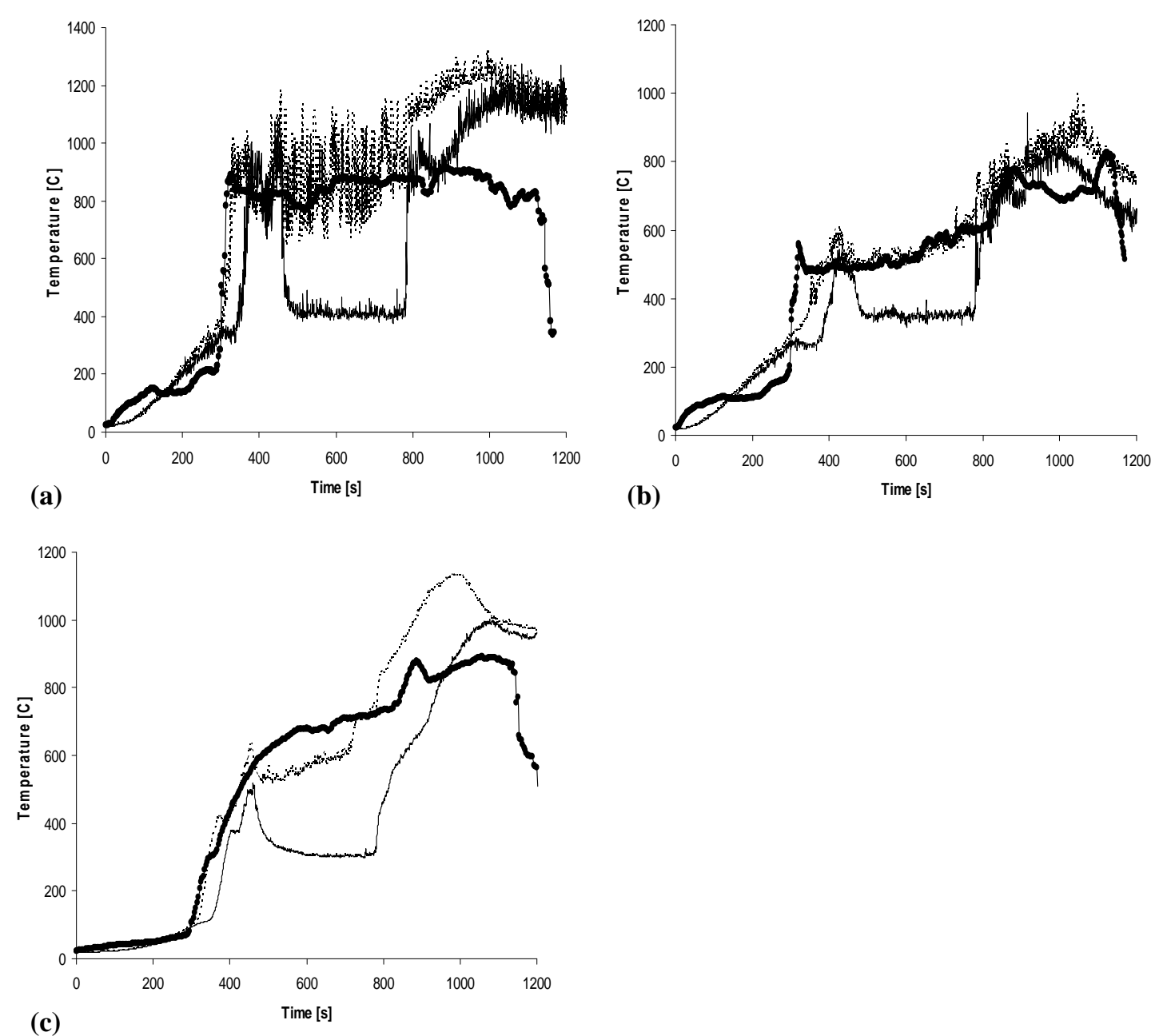

Fig. 7. Time variations of local temperatures. Comparison between fine-grid ( $\Delta=5 \mathrm{~cm}$, solid line) and coarse-grid ( $\Delta=10 \mathrm{~cm}$, dashed line) simulations; the solid line with dot symbols represents experimental measurements [6-9]. (a) $(x, y, z)=(2.05,0.45,1.8)$ (in units of m); (b) $(x, y, z)=(1.95,3.95,1.8)$; (c)

$$
(x, y, z)=(1.75,0.0,1.9) \text {. }
$$




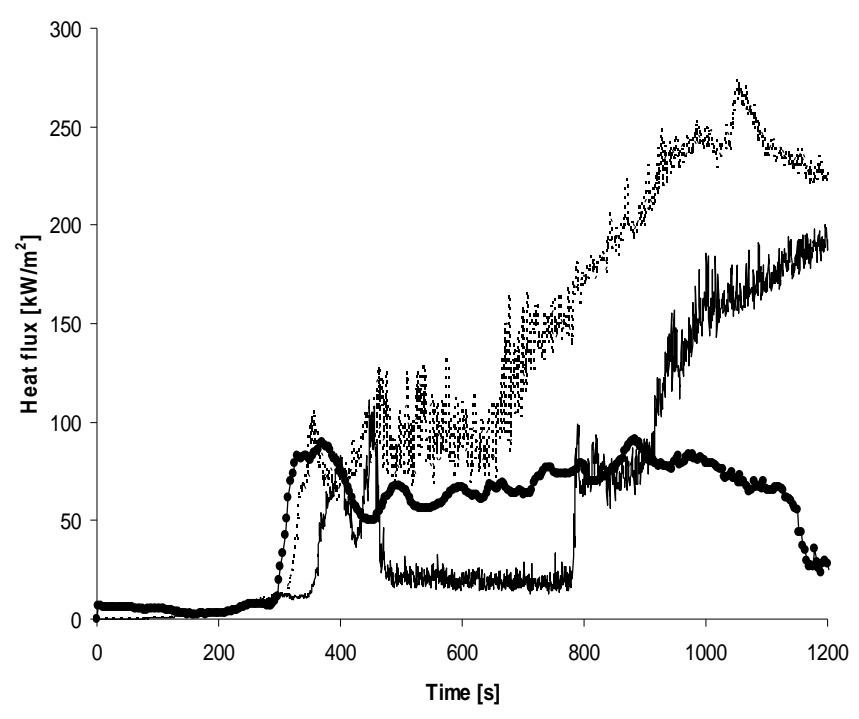

Fig. 8. Time variations of the wall surface heat flux. Comparison between fine-grid ( $\Delta=5 \mathrm{~cm}$, solid line) and coarse-grid ( $\Delta=10 \mathrm{~cm}$, dashed line) simulations; the solid line with dot symbols represents experimental measurements [6-9]. $(x, y, z)=(2.5,0.0,2.2)$.

\section{Variations of Gas and Wall Temperatures}

We now turn in the next two Sections to a comparison between FDS results and local time-resolved measurements of gas/wall temperatures as well as wall heat fluxes. While Fig. 4 suggests that the global features of the fire are relatively well simulated, the discussion below shows that the performance of the fire model is less satisfactory when considering local quantities.

Figures 7(a)-(b) present the time variations of the gas temperatures at two different locations inside the fire room. These locations are selected to provide a representative sample of upper layer results and are identified in the figure caption using a Cartesian coordinates system with origin at floor-level in the corner of the lounge defined by the kitchen and bedroom walls (this Cartesian system is illustrated in Fig. 6(a)). Results presented in Fig. 7(a) correspond to a point located between the sofa and the kitchen wall, while results in Fig. 7(b) correspond to a point located close to the windows. Figure 7(c) presents the time variations of the concrete wall temperature at a point located on the kitchen wall near the bookcase and doorways.

Figures 7(a)-(c) show that while comparisons between experimental data and numerical results are good in the pre-flashover stage, they become poor in the post-flashover stages, especially in the $\Delta=5 \mathrm{~cm}$ solution. Note that some of the discrepancies observed in Figs. 7(a) and 7(c) are due to the persistent proximity of the simulated flames to these locations and to uncertainties about the exact flame locations. The temperature drop observed between 500 and $780 \mathrm{~s}$ in the $\Delta=5 \mathrm{~cm}$ data of Fig. 7(b) is more of a concern and suggests a decreased accuracy in the fine-grid solution.

\section{Variations of Wall Surface Heat Fluxes}

Figure 8 presents the time variations of the wall surface heat flux at a point located on the kitchen wall near the bookcase and doorways. The comparison between experimental data and numerical results is poor in the post-flashover stages, in both the $\Delta=5$ and $10 \mathrm{~cm}$ solutions. These results are due in part to the persistent proximity of the simulated flames to this location (and better results may be obtained elsewhere in the fire room); however, it serves to illustrate the challenges found in the application of more elaborate fire growth models in which the fuel mass loss rate of flammable objects/materials is calculated as a function of the fire thermal feedback. 


\section{CONCLUSION}

The present study is aimed at evaluating the application of current CFD-based fire modeling capabilities to a description of compartment fire scenarios featuring flashover, under-ventilation and window breakage. Current CFD capabilities are illustrated using the Fire Dynamics Simulator (FDS, Version 5), developed by the National Institute of Standards and Technology. The FDS performance is evaluated in a validation study using an experimental database previously developed by the University of Edinburgh; the database corresponds to the Dalmarnock fire test (test 1). The description of the flammable content in the fire room is based on a standard modeling approach in which the ignition time of flammable objects and materials is calculated while the fuel mass loss rate after ignition is prescribed.

The Dalmarnock fire test is well-suited to testing compartment fire models since it includes two transitions: a first transition to flashover and under-ventilated combustion as a result of fire growth; and a second transition to quasi-stoichiometric, partially-under-ventilated combustion following window breakage. The present study provides an analysis of the flame structure found after each one of these two transitions. Comparisons between numerical results and experimental data suggest that the global features of the fire dynamics are relatively well predicted, e.g., the timing of flashover and the response of the fire to window breakage; comparisons also indicate that local temperatures and surface heat fluxes are subject to much larger uncertainties.

In summary, the present study confirms that the greatest challenge in compartment fire modeling is found in the simulation of quasi-stoichiometric compartment fires (i.e., compartment fires with global equivalence ratios between 0.3-0.5 and 1). It also emphasizes the critical importance of predicting window breakage accurately. Finally, the study illustrates the challenges found in the development of more advanced descriptions of burning objects using thermal-feedback-sensitive models.

\section{Acknowledgments}

The authors would like to acknowledge Prof. José L. Torero and Dr. Guillermo Rein from the BRE Centre for Fire Safety Engineering at the University of Edinburgh, U.K., for many fruitful interactions and for providing the experimental data of the Dalmarnock Fire Tests.

\section{REFERENCES}

[1] Drysdale, D., An Introduction to Fire Dynamics, John Wiley \& Sons, (2 ${ }^{\text {nd }}$ ed.), 1998.

[2] Karlsson, B., and Quintiere, J. G., Enclosure Fire Dynamics, CRC Press LLC, 2000.

[3] Quintiere, J. G., Fundamentals of Fire Phenomena, John Wiley \& Sons, 2006. doi:10.1002/0470091150

[4] Salley, M.H., Dreisbach, J., Hill, K., Kassawara, R., Najafi, B., Joglar, F., Hammins, A., McGrattan, K.B., Peacock, R.D., and Gautier, B., (2007) Verification and Validation: How to Determine the Accuracy of Fire Models, Fire Protection Engineering 34:34-44.

[5] Hu, Z., Utiskul, Y., Quintiere, J.G., and Trouvé, A., “A Comparison Between Observed and Simulated Flame Structures in Poorly Ventilated Compartment Fires,” Fire Safety Science -Proceedings of the Eighth International Symposium, International Association for Fire Safety Science, 2005, pp. 1193-1204.

[6] Rein, G., Abecassis-Empis, C., Amundarain, A., Biteau, H., Cowlard, A., Chan, A., Jahn, W., Jowsey, A., Reszka , P., Steinhaus, T., Carvel, R.O., Welch, S., Torero, J.L., Stern-Gottfried, J., Hume, B., Coles, A., Lazaro, M., Alvear, D., Capote, J.A., Desanghere, S., Joyeux, D., Ryder, N.L., Schemel, C., and Mowrer, F., "Round-Robin Study of Fire Modelling Blind-Predictions Using the Dalmarnock Fire Experiment," Proceedings of the Fifth International Seminar on Fire and Explosion Hazards, The University of Edinburgh, U.K., 2007.

[7] Rein, G., Abecassis-Empis, C., Amundarain, A., Biteau, H., Cowlard, A., Chan, A., Jahn, W., Jowsey, A., Reszka , P., Steinhaus, T., Carvel, R.O., Welch, S., Torero, J.L., Stern-Gottfried, J., Hume, B., Coles, A., Lazaro, M., Alvear, D., Capote, J.A., Desanghere, S., Joyeux, D., Ryder, N.L., Schemel, C., and Mowrer, F., "Round-Robin Study of Fire Modelling Blind-Predictions 
Using the Dalmarnock Fire Experiment," Advanced Research Workshop on Fire Computer Modeling, Capote, J.A. (ed.), GIDAI, The University of Cantabria, Spain, 2007, p. 65.

[8] Jahn, W., Snorrason, D., Abecassis-Empis, C., Rein, G., Welch, S., and Torero, J., "A Posteriori Modelling of the Dalmarnock Fire Tests," Advanced Research Workshop on Fire Computer Modeling, Capote, J.A. (ed.), GIDAI, The University of Cantabria, Spain, 2007, p. 169.

[9] The Dalmarnock Fire Tests: Experiments and Modelling, Rein,G., Abecassis-Empis C., Carvel, C. (eds.), School of Engineering and Electronics, University of Edinburgh, 2007.

[10] McGrattan, K.B., Floyd, J.E., Forney, G.P., Baum, H.R., and Hostikka, S., "Improved Radiation and Combustion Routines for a Large Eddy Simulation Fire Model,” Fire Safety Science -Proceedings of the Seventh International Symposium, International Association for Fire Safety Science, 2003, pp. 827-838.

[11] McGrattan, K.B., Klein, B., Hostikka, S., and Floyd, J.E., "Fire Dynamics Simulator (Version 5) User's Guide," National Institute of Standards and Technology Report NIST Special Publication 1019-5, Gaithersburg, MD, USA, 2007.

[12] McGrattan, K.B., Hostikka, S., Floyd, J.E., Baum, H.R., and Rehm, R.G., "Fire Dynamics Simulator (Version 5) - Technical Reference Guide,” National Institute of Standards and Technology Report NIST Special Publication 1018-5, Gaithersburg, MD, USA, 2007.

[13] Forney, G.P., “User’s Guide for Smokeview Version 5 - A Tool for Visualizing Fire Dynamics Simulation Data," National Institute of Standards and Technology Report NIST Special Publication 1017-1, Gaithersburg, MD, USA, 2008.

[14] Joshi, A.A., and Pagni, P.J., "User’s Guide to BREAK1, The Berkeley Algorithm for Breaking Window Glass in a Compartment Fire," National Institute of Standards and Technology Report NIST-GCR-91-596, Gaithersburg, MD, USA, 1991.

[15] Lawson, J.R., Walton, W.D., Twilley, W.H., "Fire Performance of Furnishings as Measured in the NBS Furniture Calorimeter. Part 1," National Institute of Standards and Technology Report NBSIR 83-2787, Gaithersburg, MD, USA, 1983.

[16] Incropera, F.P., DeWitt, D.P., Fundamentals of Heat and Mass Transfer, John Wiley \& Sons, (5 ed.), 2002.

[17] Babrauskas, V., Ignition Handbook, Fire Science Publishers, Issaquah WA, USA, 2003.

[18] FIRESTARR Final Report, European Commission Project, CEN/TC256 and CENELEC/TC9X, Société Nationale des Chemins de Fer, Direction du Matériel et de la Traction, France, 2001.

[19] Ohlemiller, T.J., Mulholland, G.W., Maranghides, A., Filliben, J J., Gann, R.G., "Fire Tests of Single Office Workstations. Federal Building and Fire Safety Investigation of the World Trade Center Disaster,” National Institute of Standards and Technology Report NIST NCSTAR 1-5C, Gaithersburg, MD, USA, 2005.

[20] Bundy, M., Ohlemiller, T., "Full-Scale Flammability Measures for Electronic Equipment," National Institute of Standards and Technology Report NIST Technical Note 1461, Gaithersburg, MD, USA, 2004.

[21] Madrzykowski, D., Walton, W.D., "Cook County Administration Building Fire, 69 West Washington, Chicago, Illinois, October 17, 2003: Heat Release Rate Experiments and FDS Simulations,” National Institute of Standards and Technology Report NIST Special Publication 1021, Gaithersburg, MD, USA, 2004. 